\title{
Is simple decompression enough for the treatment of idiopathic cubital tunnel syndrome: A prospective comparative study analyzing the outcomes of simple decompression versus partial medial epicondylectomy
}

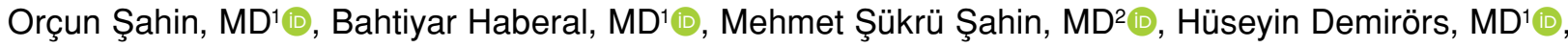 \\ İlhami Kuru, $\mathrm{MD}^{1}{ }^{1}$, İsmail Cengiz Tuncay, $\mathrm{MD}^{1}{ }^{1}$ \\ ${ }^{1}$ Department of Orthopedics and Traumatology, Medicine Faculty of Başkent University, Ankara, Turkey \\ ${ }^{2}$ Department of Orthopedic Surgery, Başkent University Alanya Application and Research Center, Alanya, Turkey
}

Cubital tunnel syndrome (CuTS) is the second most commonly seen entrapment neuropathy of the upper limb in adults. ${ }^{[1]}$ Many surgical procedures have been described in the literature, including simple decompression; ${ }^{[2]}$ submuscular; ${ }^{[3]}$ intramuscular; ${ }^{[4]}$ or subcutaneous, ${ }^{[5]}$ ulnar nerve transposition; medial epicondylectomy $;^{[6,7]}$ and endoscopic in-situ cubital tunnel release. ${ }^{[8-10]}$

Although there are a number of different studies in the literature comparing different kinds of surgical techniques for the treatment of idiopathic CuTS, the best surgical technique for ulnar nerve decompression has not yet been established. Simple decompression of the ulnar nerve at its entrance to the cubital

Received: February 20, 2020

Accepted: June 25, 2020

Published online: September 11, 2020

Correspondence: Orçun Sahin, MD. Bașkent Üniversitesi Tıp Fakültesi Ortopedi ve Travmatoloji Anabilim Dalı, 06490 Bahçelievler, Ankara, Türkiye.

E-mail: drorcunsahin@gmail.com

Doi: $10.5606 /$ ehc. 2020.74400

Citation: Sahin O, Haberal B, Sahin MS, Demirörs $H$, Kuru i, Tuncay iC. Is simple decompression enough for the treatment of idiopathic cubital tunnel syndrome: A prospective comparative study analyzing the outcomes of simple decompression versus partial medial epicondylectomy. Jt Dis Relat Surg 2020;31(3):523-531.

(02020 All right reserved by the Turkish Joint Diseases Foundation

This is an open access article under the terms of the Creative Commons Attribution-NonCommercial License, which permits use, distribution and reproduction in any medium, provided the original work is properly cited and is not used for commercial purposes (http://creativecommons.org/licenses/by-nc/4.0/).

\section{ABSTRACT}

Objectives: This study aims to compare the clinical and functional outcomes of simple in-situ decompression and partial medial epicondylectomy for the treatment of idiopathic cubital tunnel syndrome (CuTS).

Patients and methods: Between March 2014 and December 2016, 71 patients (31 males, 40 females; mean age 46.7 years; range, 38 to 62 years) with CuTS scheduled to undergo simple in-situ decompression (group 1) or partial medial epicondylectomy (group 2) were prospectively reviewed. All patients were analyzed with clinical examination (Tinel sign, Froment's and Wartenberg's signs, elbow flexion test, subluxation), and McGowan scores before and after surgery. Final outcomes were reviewed with Wilson and Krout grading system.

Results: There was no significant difference between the study groups in regard to Wilson and Krout grading and McGowan scores postoperatively. Group 1 had significantly better grip and key pinch strength values compared to group 2 at the final follow-up control.

Conclusion: In-situ decompression and partial medial epicondylectomy represent efficient and safe methods for the treatment of idiopathic CuTS. When their efficiency is compared, in-situ decompression had better grip and key pinch strength values and more excellent outcomes compared to partial medial epicondylectomy.

Keywords: Cubital tunnel syndrome, in-situ decompression, medial epicondylectomy.

tunnel was first reported in the 1950s by Osborne, ${ }^{[1]}$ Feindel, and Stratford. ${ }^{[12]}$ Since then, it is widely used in clinical practice with a high success rate. Partial medial epicondylectomy with in-situ decompression was first described by Kaempffe and Farbach in $1998{ }^{[13]}$ Various studies have been published in the literature analyzing the outcomes of these techniques. 
Nevertheless, the data comparing partial medial epicondylectomy with simple decompression are scarce and inconclusive. Therefore, whether to perform just simple decompression or partial epicondylectomy with in-situ decompression is still a controversial issue with no clear-cut indications. In order to solve this issue, more studies are needed comparing the outcomes of these two techniques. To our knowledge, this is one of the first studies in the English literature comparing simple in-situ decompression with partial medial epicodylectomy. Hence, in this study, we aimed to compare the clinical and functional outcomes of simple in-situ decompression and partial medial epicondylectomy for the treatment of idiopathic CuTS.

\section{PATIENTS AND METHODS}

Between March 2014 and December 2016, all patients with CuTS scheduled to undergo simple in-situ decompression or partial medial epicondylectomy were prospectively reviewed at Medicine Faculty of Başkent University. The study protocol was approved by the Başkent University Institutional Review Board and Ethics Committee (project no: KA20/106). A written informed consent was obtained from each patient. The study was conducted in accordance with the principles of the Declaration of Helsinki.

Diagnosis of CuTS was established based on clinical findings, with subsequent confirmation using electrophysiological tests. ${ }^{[14]}$ Clinical findings included sensory disturbance in the ulnar nerve sensory zone and motor dysfunction induced by intrinsic muscle atrophy. Operative treatment was performed for patients who still had significant symptoms of tingling, pain, or weakness after at least two months of conservative treatment including two times of steroid injections ( $40 \mathrm{mg}$ methylprednisolone acetate [Depo-Medrol; Pfizer, New York, USA] and $10 \mathrm{mg}$ lidocaine hydrochloride). Before the injection, medial epicondyle and the course of the ulnar nerve were marked with a surgical marker and all steroid injections were performed with the elbow in 90 degrees of flexion and under local anesthesia by using topical vapocoolant spray, just posterior to the medial epicondyle with a no-touch technique.

As inclusion criteria, only "idiopathic CuTS" cases who had either simple in-situ decompression or partial medial epicondylectomy surgeries were recruited for the study group. All syndromic CuTS cases (tumors, ganglion cysts, repetitive use, anatomical variations, and diseases of the neighboring blood vessels etc.) were excluded in the study group in order to prevent any bias and achieve a homogeneous study population. A total of 86 patients were enrolled for the study.
Exclusion criteria were previous decompression of the ulnar nerve $(n=1)$, other entrapment neuropathies such as cervical radiculopathy, or carpal tunnel syndrome $(n=4)$, osseous canal deformity from previous trauma or osteophytes of the elbow joint $(n=1)$, valgus instability of elbow $(n=1)$, thoracic outlet syndrome, and a follow-up period of less than 24 months $(n=8)$. Finally, a total of 71 patients (31 males, 40 females; mean age 46.7 years; range, 38 to 62 years) were found eligible for the study and two study groups were created according to the surgeries performed as group 1 (simple in-situ decompression group, $\mathrm{n}=38$ ) and group 2 (partial medial epicondylectomy group, $\mathrm{n}=33$ ).

All surgical procedures were performed in supine position and under general anesthesia by three surgeons experienced in upper extremity surgeries. The type of the surgical procedure (either in-situ decompression or partial medial epicondylectomy) was determined according to personal preference of the surgeon with a shared opinion of the patient. The indication for simple in-situ decompression was established according to the pre-/intraoperative ulnar nerve subluxation or instability. If no subluxation or instability was determined during elbow flexion, only in-situ decompression was performed. On the contrary, all partial medial epicondylectomy surgeries were performed for patients who demonstrated ulnar nerve subluxation pre- or intraoperatively about the medial epicondyle with elbow flexion, following in-situ decompression.

All simple ulnar nerve decompression operations were performed as described by Huang et al. ${ }^{[15]}$ In short, after a sterile tourniquet application, 6 to $8 \mathrm{~cm}$ medial incision was performed in-line with the posterior condylar groove. The ulnar nerve was identified and followed distally to the musculus flexor carpi ulnaris. It was decompressed in the cubital tunnel, without mobilization, up to the medial intermuscular septum in proximal direction and up to the two heads of the flexor carpi ulnaris distally.

Each patient had an in-situ ulnar nerve release with partial medial epicondylectomy as described by Heithoff et al., ${ }^{[16]}$ with preservation of the medial collateral ligament. After the ulnar nerve decompression procedure, the medial epicondyle was exposed with subperiosteal dissection. After adequate exposure, the medial epicondyle was partially removed approximately $7 \mathrm{~mm}$ from its tip using a 3/8-inch osteotome, avoiding disturbing the anterior medial collateral ligament (Figure 1). The amount of resection should be sufficient to allow a spontaneous 

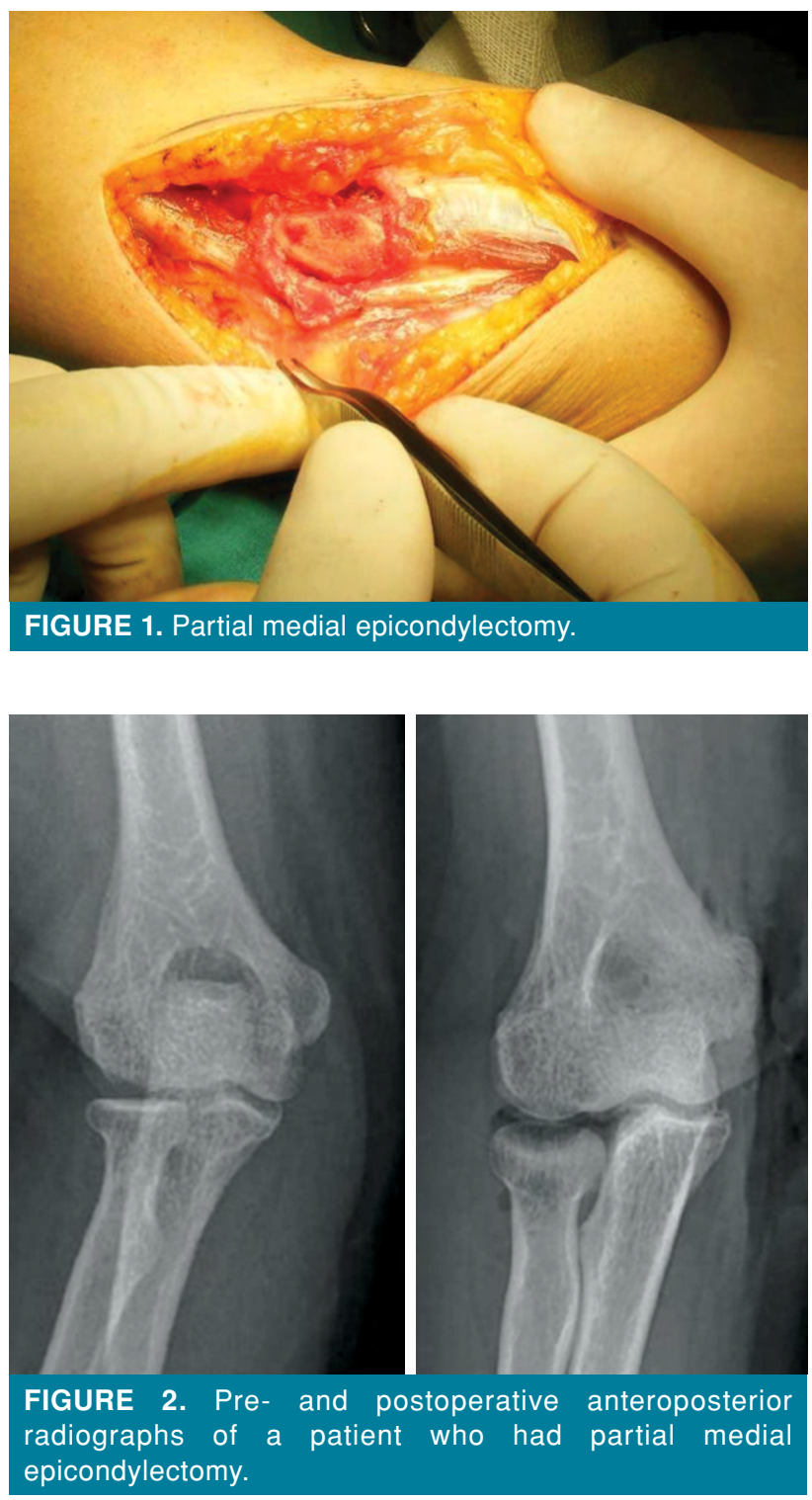

anterior translation of the ulnar nerve at flexion, but not excessively so, in order to avoid damage to the medial collateral ligament (Figure 2).

Postoperatively, a soft bandage was applied for two days, followed by encouraged motion as tolerated by the patient with the basic home exercises for the operated upper extremity. No support was obtained from the physical treatment department in the follow-up period.

Postoperatively, follow-up visits were performed at two weeks, six weeks, six months, and annually, thereafter. All patients were followed-up for at least 24 months.

All clinical assessments were performed by one investigator blinded to the surgical procedure. Data including the duration of symptoms, the occupation of the patients, Tinel sign over the course of the ulnar nerve in the postcondylar groove, Froment's and Wartenberg's signs, elbow flexion test, and palpation for any subluxation of the nerve were recorded preand postoperatively. Grip strength and key pinch strength were also evaluated (Jamar dynamometer; Preston, Jackson, MI, USA) by the same investigator preoperatively and at the final follow-up visit.

Two independent investigators evaluated the patients' functional status pre- and postoperatively by the use of the modified McGowan grading system (Table I). ${ }^{[17]}$ The postoperative state of the patients was classified by using the modified Wilson and Krout grading system, in which excellent means minimal motor and sensory changes and no tenderness at the incision site, good means occasional ache and mild sensory or motor changes, fair means improved but persistent sensory or motor changes, and poor means no improvement or a worsened condition. Patient satisfaction was also evaluated with the status of the patients' return to former job/daily activities.

\section{Statistical analysis}

Statistical comparisons between the study groups on demographic factors including age, sex and duration of symptoms, the preoperative status, and outcome parameters were performed by using the Student's t-test or the Pearson's chi-square test. All calculations were performed using the SPSS for Windows version 14.0 software (SPSS Inc,. Chicago, IL, USA). P values less than 0.05 were considered statistically significant.

\section{RESULTS}

The average follow-up period for the study group was 27.3 (range, 24 to 36 ) months. The occupational survey of the study population revealed that there were 31 housewives $(43.6 \%), 16$ government officials $(22.5 \%), 14$ retired employees $(19.7 \%)$, seven teachers $(9.8 \%)$, and three unemployed persons $(4.2 \%)$. The most common preoperative symptom of the study

\section{TABLE I}

McGowan classification as modified by Goldberg ${ }^{[17]}$

Stage 1 Purely subjective symptoms

Stage 2 Muscle weakness and/or objective sensory signs 2A: No atrophy of intrinsic muscles

2B: Some atrophy of intrinsic muscles

Stage 3 Significant sensory and motor deficits with noticeable atrophy of intrinsic muscles 


\begin{tabular}{|c|c|c|c|c|c|}
\hline \multirow[b]{3}{*}{ Demographic features } & \multicolumn{2}{|c|}{$\begin{array}{l}\text { TABLE II } \\
\text { tudv aroun and }\end{array}$} & ical & arison $\mathrm{r}$ & \multirow[b]{3}{*}{$p$} \\
\hline & \multicolumn{2}{|c|}{ Group 1} & \multicolumn{2}{|c|}{ Group 2} & \\
\hline & $\mathrm{n}$ & Mean & $\mathrm{n}$ & Mean & \\
\hline Age (year) & & 44.7 & & 47.3 & 0.312 \\
\hline \multicolumn{6}{|l|}{ Sex } \\
\hline Male & 17 & & 14 & & 0.911 \\
\hline Female & 22 & & 18 & & 0.567 \\
\hline Follow-up (month) & & 26.5 & & 27.9 & 0.219 \\
\hline \multicolumn{6}{|l|}{ Side } \\
\hline Left & 12 & & 14 & & 0.438 \\
\hline Right & 21 & & 24 & & 0.067 \\
\hline Duration of symptoms (month) & & 13.2 & & 13.9 & 0.145 \\
\hline
\end{tabular}

group was paresthetic pain $(\mathrm{n}=58,81.7 \%)$. All patients had idiopathic CuTS approved by electromyography (EMG) studies. The average duration of symptoms of the study population was 13.7 (range, 8 to 17) months. Right and left elbows were operated in 45 and 26 patients (63.3\% and $36.7 \%$, respectively). Among the patients, $49(69 \%)$ had surgery for the dominant extremity (28 in group 1 and 21 in group 2). There were no bilateral cases. The demographic features of each study group including the duration of symptoms and statistical comparison results were summarized in Table II.

There were two patients in group 2 with prolonged wound drainage postoperatively which was treated with daily wound dressing changes. No patients needed a second surgery for any complications. The Tinel sign was present in 67 patients. The elbow flexion test was positive in 59 patients, whereas 18 patients had a Froment's sign and nine had a Wartenberg's sign. Local tenderness was present around the cubital tunnel region in 70 patients, and four patients had palpable subluxation of the ulnar nerve. The preoperative clinical data for each study group including Tinel's sign over the course of the ulnar nerve in the postcondylar groove, Froment and Wartenberg's signs, elbow flexion test, and palpation for any subluxation were summarized in Table III. There was no statistically significant difference between the study groups in regard to clinical findings preoperatively (Table III). The postoperative clinical status of patients in each group at the final control is shown in Table IV. Although there was no statistically significant difference between the postoperative clinical findings of the study groups (Table IV), there was a statistically significant difference between all the pre- and postoperative clinical findings $(\mathrm{p}<0.005$ for all parameters).

The average grip strength and key pinch strength values for the study groups pre- and postoperatively and the statistical comparison results were summarized in Table V. Group 1 had significantly better grip and key pinch strength values compared to group 2 at the final follow-up control $(p<0.005)$. This significant difference in strength values between the study groups mostly resulted from the muscle repair after epicondylectomy in group 2 which may have led to weakness of the hand grip and key pinch strengths of the operated arm.

\begin{tabular}{|c|c|c|c|c|}
\hline \multicolumn{5}{|c|}{$\begin{array}{l}\text { TABLE III } \\
\text { udy groups }\end{array}$} \\
\hline & Group 1 & Group 2 & Total & \\
\hline Preoperative clinical findings & $\mathrm{n}$ & $\mathrm{n}$ & $\mathrm{n}$ & $p$ \\
\hline Tinel's sign & 36 & 31 & 67 & 0.367 \\
\hline Elbow flexion test & 29 & 30 & 59 & 0.712 \\
\hline Froment's sign & 10 & 8 & 18 & 0.143 \\
\hline Wartenberg's sign & 4 & 5 & 9 & 0.067 \\
\hline Nerve subluxation & 2 & 2 & 4 & 0 \\
\hline
\end{tabular}




\begin{tabular}{|c|c|c|c|c|}
\hline \multicolumn{5}{|c|}{$\begin{array}{l}\text { TABLE IV } \\
\text { study groups }\end{array}$} \\
\hline & Group 1 & Group 2 & Total & \\
\hline Preoperative clinical findings & $\mathrm{n}$ & $\mathrm{n}$ & $\mathrm{n}$ & $p$ \\
\hline Tinel's sign & 1 & 2 & 3 & 0.831 \\
\hline Elbow flexion test & 0 & 1 & 1 & 0.072 \\
\hline Froment's sign & 0 & 0 & 0 & 0 \\
\hline Wartenberg's sign & 1 & 0 & 1 & 0.08 \\
\hline Nerve subluxation & 0 & 0 & 0 & 0 \\
\hline
\end{tabular}

\begin{tabular}{|c|c|c|c|c|c|}
\hline \multicolumn{6}{|c|}{ 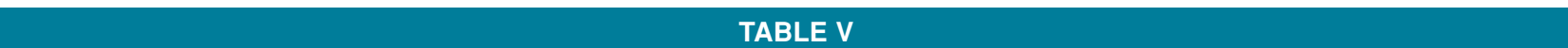 } \\
\hline & \multicolumn{2}{|c|}{ Group 1} & \multicolumn{2}{|c|}{ Group 2} & \multirow{2}{*}{$\begin{array}{c}\text { P values between the } \\
\text { study groups } \\
p\end{array}$} \\
\hline & Preoperative & Postoperative & Preoperative & Postoperative & \\
\hline & $\%$ & $\%$ & $\%$ & $\%$ & \\
\hline Grip strength* & 71 & 89 & 69 & 75 & $<0.005$ \\
\hline Key pinch strength* & 74 & 90 & 72 & 80 & $<0.005$ \\
\hline$P$ values within the study groups & \multicolumn{2}{|c|}{$\mathrm{p}<0.005$} & \multicolumn{2}{|c|}{$\mathrm{p}<0.005$} & \\
\hline
\end{tabular}

Among the 71 patients, there was only one patient with a preoperative McGowan score of stage 1, 42 patients of stage $2 \mathrm{~A}, 20$ patients of stage $2 \mathrm{~B}$, and eight patients of stage 3. Postoperatively, a total of 68 patients $(95.8 \%)$ had improved McGowan scores. Among the three patients who had no improvement, one had stage $2 \mathrm{~B}$ and two had stage 3 CuTS. All these patients without improvement were in group 2 . Although there was a statistically significant difference for the McGowan scores pre- and postoperatively $(\mathrm{p}<0.005)$, no significant difference was found in regard to McGowan scores between the study groups postoperatively $(\mathrm{p}=0.317)$.

The modified Wilson and Krout grading system revealed that a total of 34 patients had excellent outcomes (20 patients in group 1 and 14 patients in group 2), 33 patients had good outcomes (19 patients in group 1 and 14 patients in group 2), and four patients had fair outcomes (one patient in group 1 and three patients in group 2) at the final follow-up visit. There was no patient with poor outcome. All patients were able to return to their former job/daily activity routines in the follow-up period. There was a significant difference between the study groups in regard to Wilson and Krout grading after surgery $(\mathrm{p}=0.002)$. Group 1 had significantly better final outcomes with no pain and excellent outcomes compared to group 2.

\section{DISCUSSION}

This study is one of the first studies in the literature that prospectively compared single in-situ decompression with partial medial epicondylectomy with a minimum of two years of follow-up.

Idiopathic CuTS is one of the most commonly seen neurological problems of the upper limb in the outpatient clinics. The majority of CuTS patients with weakness/numbness of the hand or elbow and forearm pain while doing daily activities are commonly treated with conservative methods. Nevertheless, some patients with CuTS require surgical treatment due to failure of these conservative treatment methods. In the literature, several studies emphasized that the decision for the surgical treatment may also depend on the nerve conduction velocity of the ulnar nerve, generally accepted as below $40 \mathrm{~mm}$ per second derived from the EMG studies. ${ }^{[18-24]}$ In our study, we used EMG findings for the diagnostic purposes only and the decision of surgical treatment was established according to the failure of conservative treatment including the steroid injections for at least two months regardless of the EMG findings. Future prospective comparative studies should be designed including the patients who have surgical treatment according to the EMG findings. Today, although the literature contains numerous studies about the outcomes of patients who 
had surgical treatment for idiopathic CuTS, the gold standard surgical treatment option is still a matter of discussion.

Surgical treatment of idiopathic CuTS has been widely used in clinical practice with various methods in a wide array including simple in-situ decompression, decompression with anterior transpositions (intramuscular, submuscular, or subcutaneous), and medial epicondylectomy. Nevertheless, there are no clear-cut indications for different surgical techniques in the literature due to heterogeneous study populations, different outcome measures with short follow-up periods, and lack of prospective comparative studies.

Simple in-situ decompression and medial epicondylectomy are the two most widely used surgical techniques for the treatment of idiopathic CuTS with a reported success rate of more than $85 \%$. Although prospective studies and meta-analyses comparing simple in-situ decompression and transpositions revealed that simple in-situ decompression is as equally effective as transpositions, the comparative data between simple in-situ decompression and medial epicondylectomy are very scarce and inconclusive in the literature. Hence, prospective comparative studies are needed for the evaluation of these two surgical procedures in order to understand the best option for the surgical treatment of idiopathic CuTS.

Many surgeons prefer simple in-situ decompression for having an easy technique and requiring a smaller incision, which causes less tissue damage, preserves nerve vascularization, and requires less rehabilitation time. ${ }^{[15,18,25]}$ In the literature, most of the studies reported that more than $80 \%$ of patients had satisfactory outcomes with simple in-situ decompression. In a recent meta-analysis by Zlowodzki et al., ${ }^{[25]}$ randomized, controlled trials comparing the simple decompression with the anterior transposition (submuscular or subcutaneous) were analyzed and it was concluded that there were no significant differences for the postoperative outcomes, which supports the use of a simple in-situ decompression. ${ }^{[25]}$ On the contrary, one of the most controversial issues of in-situ decompression is the subluxation of the ulnar nerve with elbow flexion after surgery. Although there are considerable data about the subluxation of the ulnar nerve after in-situ decompression, there is still controversy about the real incidence and possible risk factors of this postoperative complication. Most surgeons perform anterior translation or medial epicondylectomy if they observe ulnar nerve subluxation during elbow flexion. However, there is insufficient evidence in the literature to suggest that anterior translation or medial epicondylectomy is superior to in-situ decompression in regard to ulnar nerve subluxation. In a study by Childress, ${ }^{[26]}$ it was shown that the ulnar nerve subluxes naturally in $16.2 \%$ of the normal population. In another cadaveric study by Butler et al., ${ }^{[27]}$ an in-situ ulnar nerve decompression was performed in 10 fresh frozen right cadaver arms and it was concluded that in-situ ulnar nerve decompression from the flexor carpi ulnaris aponeurosis to the intermuscular septum did not result in significant ulnar nerve translation or subluxation. In the current study, there was no postoperative complication of ulnar nerve subluxation for the in-situ decompression group in a minimum of two years of follow-up. ${ }^{[28]}$ Therefore, we believe that for the idiopathic CuTS, simple in-situ decompression does not have any risk of ulnar nerve subluxation only if there is no local problem like as osteophytes, scarring or alignment problems of the elbow.

Medial epicondylectomy was first described in 1959 by King and Morgan ${ }^{[6]}$ as a "mini anterior transposition" and since then, most of the studies in the literature have confirmed the success rates between $72 \%$ and $94 \% .{ }^{[29]}$ Compared with decompression plus anterior transposition, medial epicondylectomy better preserves the blood supply of the ulnar nerve, causes less injury to the nerve, and preserves the small proximal nerve branches that might be sacrificed with an anterior transposition. On the other hand, total medial epicondylectomy, which results in removal of $40 \%$ of the medial epicondyle (until the medial margin of the trochlea), puts the anterior medial collateral ligament (AMCL) at risk leading to elbow instability. Additionally, total medial epicondylectomy may result in medial elbow pain, ulnar nerve subluxation, flexor-pronator weakness, and elbow flexion contracture. ${ }^{[19,30]}$ In order to solve these problems, partial medial epicondylectomy was described by Kaempffe and Farbach ${ }^{[13]}$ in 1998, which resects approximately 6 to $7 \mathrm{~mm}$ of the epicondyle (20 to $40 \%$ ) preserving the entire anterior medial collateral ligament. The terms partial medial epicondylectomy (6-7 $\mathrm{mm}$ of the epicondyle) and minimal medial epicondylectomy $(<6 \mathrm{~mm}$ of the epicondyle) have been used rather interchangeably in the literature. ${ }^{[19,31-33]}$ Although these two types of techniques are somehow similar, in that each procedure describes a resection of the medial epicondyle that is less than $40 \%$ of the epicondyle, we believe that minimal medial epicondylectomy resection is not enough for the ulnar nerve to simultaneously transpose through the anterior part of the elbow while elbow flexion, leading to the recurrence of the CuTS in the postoperative period. For this reason, 
if we want to perform epicondylectomy, we prefer partial epicondylectomy to warrant the spontaneous ulnar nerve transposition while elbow flexion.

The literature contains various studies in favor of partial medial epicondylectomy with a success rate similar to total epicondylectomy in regard to alleviation of symptoms and better stability of the elbow. In 2000, Amako et al. ${ }^{[31]}$ compared minimal medial epicondylectomy with total epicondylectomy. Although the outcomes were similar with respect to alleviation of postoperative symptoms, $74 \%$ of the total epicondylectomy patients (10/14) demonstrated valgus instability of the elbow, and $20 \%$ of those patients $(2 / 10)$ were symptomatic. Nevertheless, the minimal epicondylectomy group demonstrated no instability postoperatively. Thus the authors concluded that minimal medial epicondylectomy is a safer procedure with comparable outcomes to total medial epicondylectomy. In another study by Kim et al., ${ }^{[30]} 25$ patients treated with minimal medial epicondylectomy for advanced CuTS were analyzed with a minimum follow-up of 12 months. The authors reported that 23 of the 25 patients improved at least one McGowan stage with no complications, such as medial elbow instability. Consequently, it was stated that minimal medial epicondylectomy is an effective treatment even for patients with moderate to severe CuTS. A systematic review by O'Grady et al. ${ }^{[34]}$ reviewed 21 case series reported on 886 medial epicondylectomies. Among these studies, the mean percentage of patients obtaining improvement of one or more McGowan stages was reported as $79 \%$ and the mean percentage for those obtaining a good/excellent Wilson and Krout stage of outcomes was reported as $83 \%$. In our study, we also found that medial epicondylectomy patients had over $80 \%$ of good/ excellent outcomes according to Wilson and Krout grading system. Nevertheless, O'Grady's study also stated that the studies of medial epicondylectomy do not have any standard outcome measures and more studies are needed to understand the real effectiveness of medial epicondylectomy surgeries. We believe that the current study may be a step for this with future comparable studies.

The literature also contains various studies with long-term follow-ups of medial epicondylectomy, reporting a functional improvement in approximately $90 \%$ of patients. ${ }^{[32,35,36]}$ For partial epicondylectomies, Erol et al. ${ }^{[35]}$ reported $94 \%$ excellent and good results in 17 elbows in a follow-up period of over two years. In another study by Göbel et al., ${ }^{[32]}$ an overall success rate of $94 \%$ was reported $(79 \%$ excellent and good results) in 66 elbows in a mean follow-up of 27 months. We had comparable results with the literature with an $85 \%$ of excellent and good outcomes for the medial epicondylectomy group.

One of the most emphasized problems in the literature after medial epicondylectomy is the pain and tenderness at the surgical area leading to flexor/ pronator weakness in the postoperative period. Kaempffe and Farbach ${ }^{[13]}$ reported medial epicondylar tenderness in $44 \%$ of their patients at an average of 11 months after partial medial epicondylectomy surgery. Manske et al. ${ }^{[37]}$ reported prolonged and persistent discomfort at the operative site due to healing bone. In another study by Efstathopoulos DG, ${ }^{[19]} 80$ elbows with CuTS were retrospectively analyzed and almost half of the patients (45\%) reported mild pain at the six-month follow-up. Another problem of medial epicondylectomy is the amount of bone resection. It is commonly stated in the literature that a $7 \mathrm{~mm}$ of epicondylar resection is enough for the ulnar nerve transposition without the risk of damaging the AMCL. Nevertheless, this $7 \mathrm{~mm}$ of resection is mostly dependent on patient factors including sex, anatomical variations of the distal humerus, and even body mass indices. It is very commonly accepted in the surgical practice that the patient's characteristics should be kept in mind during surgery and if necessary, a more thicker bone resection should be performed without damaging the AMCL. In the current study, partial medial epicondylectomy was performed for patients who demonstrated ulnar nerve subluxation about the medial epicondyle intraoperatively, following in-situ decompression; and, we almost always controlled the tracking of the ulnar nerve while elbow flexion intraoperatively to understand if the epicondylectomy was sufficient or not. If we believed that it was not sufficient, we resected only slightly more medial epicondyle without damaging the AMCL. Consequently, none of the patients in the partial medial epicondylectomy group had valgus instability postoperatively. Nevertheless, partial medial epicondylectomy group had statistically more pain and tenderness compared to simple in-situ decompression group which had better Wilson and Krout grading scores.

Although the literature contains a wide array of studies comparing different surgical procedures for the treatment of CuTS, the comparative data between medial epicondylectomy and simple in-situ decompression for the treatment of solely idiopathic CuTS are very scarce and inconclusive.

In a recent meta-analysis by Zlowodzki et al., ${ }^{[25]}$ four randomized comparative studies between anterior transposition and in-situ simple decompression for 
the treatment of idiopathic CuTS were analyzed. The results of this meta-analysis revealed that there is no difference in motor nerve-conduction velocities or clinical outcome scores between simple decompression and ulnar nerve transposition. The authors suggest that simple decompression of the ulnar nerve is a reasonable alternative to anterior transposition for the surgical management of ulnar nerve compression at the elbow. In another meta-analysis by Macadam et al., ${ }^{[38]} 10$ randomized controlled trials comparing simple decompression with anterior transposition were analyzed. The authors concluded that there was no statistically significant difference between the procedures. Additionally, a systematic review published in 2000 by Mowlavi et al. ${ }^{[39]}$ also grouped patients from 30 studies into categories of symptom severity. The authors stated that for minimum-staged patients, all modalities produced similar degrees of satisfaction. Nevertheless, for severe-staged patients, current therapeutic modalities were not consistently effective, with medial epicondylectomy producing the poorest operative result. The current study also revealed comparative outcomes with the literature. In our study, simple decompression group had significantly better grip and key pinch strength values compared to medial epicondylectomy at the final follow-up control with significantly better outcomes with no pain and excellent outcomes. The reason for this weakness may be the type of the muscle repair technique. Thus we believe that using a different muscle repair technique can be practiced in future studies to solve this problem.

The failure of these two techniques and recurrence of the CuTS are also major drawbacks of this pathology leading to patient dissatisfaction. Although the failure rates are definitely low compared with the other nerve entrapment syndromes (overall recurrence rate was $10 \%$ in 10-year period), the definitive treatment plan is a matter of discussion. The most common reason for a failure is reported as insufficient decompression of the ulnar nerve along the cubital tunnel. Accordingly, we believe that if any failure and recurrence occur, a meticulous control of other pathologies should be carried out and if necessary, a second-look revision surgery with a more extensive approach should be performed.

There are some limitations that must be emphasized for this study. First of all, the study contained only simple decompression and medial epicondylectomy. Other treatment options were not analyzed. Secondly, no postoperative EMG studies were performed to understand the nerve conduction velocities. In our study, postoperative nerve healing was analyzed by the time to return to work and McGowan stages, which predominantly evaluate the clinical and functional statuses of the patients. Thirdly, all surgeries were performed independently by two surgeons. Although surgical procedures were standardized, it may be a factor that may have led to different surgical outcomes. Fourthly, no cost-utility analysis was performed for the current study due to the lack of the data about the cost of the surgical procedures and the high variety of the health insurance programs with different coverage. Finally, only a limited number of factors were analyzed; the inclusion of other factors could have provided more valuable information. For example, the anatomical configuration of the cubital tunnel may also play an important part in the development of postoperative ulnar nerve instability, and further studies could be performed in this aspect. We also did not analyze specific patient characteristics including body mass indices and smoking habits. It is well known in the literature that particularly smoking can influence the outcomes of treatment methods for CuTS.

In conclusion, the current study reported the comparative clinical and functional outcomes of idiopathic CuTS treated by either in-situ decompression or partial medial epicondylectomy with a minimum of two years of follow-up. In-situ decompression and partial medial epicondylectomy represent efficient and safe methods for the treatment of idiopathic CuTS. In long-term, these two surgical methods for CuTS have a great potential for patients with high effectiveness and low complication rates. Patients' satisfaction is also very high in long-term follow-up with very scarce recurrence or no elbow instability. When their efficiency is compared, in-situ decompression had better grip and key pinch strength values and more excellent outcomes compared to partial medial epicondylectomy. For these reasons, we believe that although the two surgical procedures have satisfactory outcomes, performing only in-situ decompression may be adequate for selected cases of idiopathic CuTS. Further prospective comparative studies are needed with larger sample sizes and different patient characteristics to have more definitive outcomes.

\section{Declaration of conflicting interests}

The authors declared no conflicts of interest with respect to the authorship and/or publication of this article.

\section{Funding}

The authors received no financial support for the research and/or authorship of this article. 


\section{REFERENCES}

1. Mondelli M, Giannini F, Ballerini M, Ginanneschi F, Martorelli E. Incidence of ulnar neuropathy at the elbow in the province of Siena (Italy). J Neurol Sci 2005;234:5-10.

2. Dellon AL. Review of treatment results for ulnar nerve entrapment at the elbow. J Hand Surg Am 1989;14:688-700.

3. Dellon AL, Coert JH. Results of the musculofascial lengthening technique for submuscular transposition of the ulnar nerve at the elbow. J Bone Joint Surg [Am] 2004;86-A Suppl 1:169-79.

4. Kleinman WB, Bishop AT. Anterior intramuscular transposition of the ulnar nerve. J Hand Surg Am 1989;14:972-9.

5. Eaton RG, Crowe JF, Parkes JC 3rd. Anterior transposition of the ulnar nerve using a non-compressing fasciodermal sling. J Bone Joint Surg [Am] 1980;62:820-5.

6. King T, Morgan FP. Late results of removing the medial humeral epicondyle for traumatic ulnar neuritis. J Bone Joint Surg [Br] 1959;41:51-5.

7. Neblett C, Ehni G. Medial epicondylectomy for ulnar palsy. J Neurosurg 1970;32:55-62.

8. Hoffmann R, Siemionow M. The endoscopic management of cubital tunnel syndrome. J Hand Surg Br 2006;31:23-9.

9. Krishnan KG, Pinzer T, Schackert G. A novel endoscopic technique in treating single nerve entrapment syndromes with special attention to ulnar nerve transposition and tarsal tunnel release: clinical application. Neurosurgery 2006;59(1 Suppl 1):ONS89-100.

10. Porcellini G, Paladini P, Campi F, Merolla G. Arthroscopic neurolysis of the ulnar nerve at the elbow. Chir Organi Mov 2005;90:191-200.

11. Osborne G. Ulnar neuritis. Postgrad Med J 1959;35:392-6.

12. Feindel W, Stratford J. Cubital tunnel compression in tardy ulnar palsy. Can Med Assoc J 1958;78:351-3.

13. Kaempffe FA, Farbach J. A modified surgical procedure for cubital tunnel syndrome: partial medial epicondylectomy. J Hand Surg Am 1998;23:492-9.

14. Novak CB, Lee GW, Mackinnon SE, Lay L. Provocative testing for cubital tunnel syndrome. J Hand Surg Am 1994;19:817-20.

15. Huang JH, Samadani U, Zager EL. Ulnar nerve entrapment neuropathy at the elbow: simple decompression. Neurosurgery 2004;55:1150-3.

16. Heithoff SJ, Millender LH, Nalebuff EA, Petruska AJ Jr. Medial epicondylectomy for the treatment of ulnar nerve compression at the elbow. J Hand Surg Am 1990;15:22-9.

17. Goldberg BJ, Light TR, Blair SJ. Ulnar neuropathy at the elbow: results of medial epicondylectomy. J Hand Surg Am 1989;14:182-8.

18. Bartels RH, Verhagen WI, van der Wilt GJ, Meulstee J, van Rossum LG, Grotenhuis JA. Prospective randomized controlled study comparing simple decompression versus anterior subcutaneous transposition for idiopathic neuropathy of the ulnar nerve at the elbow: Part 1. Neurosurgery 2005;56:522-30.

19. Efstathopoulos DG, Themistocleous GS, Papagelopoulos PJ, Chloros GD, Gerostathopoulos NE, Soucacos PN. Outcome of partial medial epicondylectomy for cubital tunnel syndrome. Clin Orthop Relat Res 2006;444:134-9.

20. Keiner D, Gaab MR, Schroeder HW, Oertel J. Comparison of the long-term results of anterior transposition of the ulnar nerve or simple decompression in the treatment of cubital tunnel syndrome--a prospective study. Acta Neurochir (Wien) 2009;151:311-5.

21. Macadam SA, Bezuhly M, Lefaivre KA. Outcomes measures used to assess results after surgery for cubital tunnel syndrome: a systematic review of the literature. J Hand Surg Am 2009;34:1482-91.e5.

22. Muermans S, De Smet L. Partial medial epicondylectomy for cubital tunnel syndrome: Outcome and complications. J Shoulder Elbow Surg 2002;11:248-52.

23. O'Driscoll SW, Jaloszynski R, Morrey BF, An KN. Origin of the medial ulnar collateral ligament. J Hand Surg Am 1992;17:164-8.

24. Pavelka M, Rhomberg M, Estermann D, Löscher WN, PizaKatzer H. Decompression without anterior transposition: an effective minimally invasive technique for cubital tunnel syndrome. Minim Invasive Neurosurg 2004;47:119-23.

25. Zlowodzki M, Chan S, Bhandari M, Kalliainen L, Schubert W. Anterior transposition compared with simple decompression for treatment of cubital tunnel syndrome. A meta-analysis of randomized, controlled trials. J Bone Joint Surg [Am] 2007;89:2591-8

26. Childress HM. Recurrent ulnar-nerve dislocation at the elbow. Clin Orthop Relat Res 1975;108:168-73.

27. Butler B, Peelman J, Zhang LQ, Kwasny M, Nagle D. The effect of in-situ decompression on ulnar nerve stability: a cadaveric study. J Hand Surg Eur Vol 2017;42:715-9.

28. Atik OŞ. Is there something new and interesting in my article? Eklem Hastalik Cerrahisi 2019;30:69.

29. Heithoff SJ. Cubital tunnel syndrome does not require transposition of the ulnar nerve. J Hand Surg Am 1999;24:898-905.

30. Kim KW, Lee HJ, RheeSH, Baek GH. Minimal epicondylectomy improves neurologic deficits in moderate to severe cubital tunnel syndrome. Clin Orthop Relat Res 2012;470:1405-13.

31. Amako $M$, Nemoto $K$, Kawaguchi $M$, Kato $N$, Arino $H$, Fujikawa K. Comparison between partial and minimal medial epicondylectomy combined with decompression for the treatment of cubital tunnel syndrome. J Hand Surg Am 2000;25:1043-50.

32. Göbel F, Musgrave DS, Vardakas DG, Vogt MT, Sotereanos DG. Minimal medial epicondylectomy and decompression for cubital tunnel syndrome. Clin Orthop Relat Res 2001;393:228-36.

33. Osterman AL, Spiess AM. Medial epicondylectomy. Hand Clin 2007;23:329-37.

34. O'Grady EE, Vanat Q, Power DM, Tan S. A systematic review of medial epicondylectomy as a surgical treatment for cubital tunnel syndrome. J Hand Surg Eur Vol 2017;42:941-5.

35. Erol B, Tetik C, Sirin E. The mid-term results of minimal medial epicondylectomy and decompression for cubital tunnel syndrome. Acta Orthop Traumatol Turc 2004;38:330-6.

36. Geutjens GG, Langstaff RJ, Smith NJ, Jefferson D, Howell CJ, Barton NJ. Medial epicondylectomy or ulnar-nerve transposition for ulnar neuropathy at the elbow? J Bone Joint Surg [Br] 1996;78:777-9.

37. Manske PR, Johnston R, Pruitt DL, Strecker WB. Ulnar nerve decompression at the cubital tunnel. Clin Orthop Relat Res 1992;274:231-7.

38. Macadam SA, Gandhi R, Bezuhly M, Lefaivre KA. Simple decompression versus anterior subcutaneous and submuscular transposition of the ulnar nerve for cubital tunnel syndrome: a meta-analysis. J Hand Surg Am 2008;33:1314.e1-12.

39. Mowlavi A, Andrews K, Lille S, Verhulst S, Zook EG, Milner S. The management of cubital tunnel syndrome: a meta-analysis of clinical studies. Plast Reconstr Surg 2000;106:327-34 